\title{
RECENT TRENDS IN THE LAND SURFACE PHENOLOGY OF AFRICA OBSERVED AT A FINE SPATIAL SCALE
}

\author{
Tracy Adole ${ }^{1}$, Jadunandan Dash ${ }^{1}$, Peter M. Atkinson $1,2,3$ \\ ${ }^{1}$ Global Environmental Change and Earth Observation Research Group, Geography and Environment, \\ University of Southampton, Southampton SO17 1BJ, UK. \\ ${ }^{2}$ Faculty of Science and Technology, Lancaster University, Lancaster LA1 4YR, UK. \\ ${ }^{3}$ School of Geography, Archaeology and Palaeoecology, Queen's University Belfast, Belfast BT7 1NN, \\ Northern Ireland, UK.
}

\begin{abstract}
This research describes the seasonal phenological pattern of Africa's vegetation and its recent trends using MODIS EVI time-series data with a relatively fine spatial resolution of $500 \mathrm{~m}$ and a long temporal range of 15 years $(2001-2015)$. The objectives were to measure the vegetation phenology of the major land cover types and determine the temporal trends across the geographical sub-regions of Africa. An improved representation of the land surface phenology (LSP) of Africa is provided, revealing which land cover types and regions have undergone significant changes in phenology over the period $2001-2015$. Recommendations are given for future studies needed to determine and distinguish all the drivers of vegetation phenology.
\end{abstract}

Index Terms - Phenology, Time-series analysis, MODIS, Africa, Vegetation.

\section{INTRODUCTION}

Monitoring vegetation dynamics is critical in understanding ecosystem functioning and consequently ecosystem services (such as agriculture, transhumance, and wildlife habitat [1], [2]). Characterising vegetation phenology, which deals with the timing of plant growth stages and their inter-annual variation, is vital in understanding vegetation dynamics and their relationship with climatic and non-climatic factors [3], [4]. Globally, in the last few decades, the study of vegetation phenology has gained much attention especially in relation to quantifying climate change impacts [5], [6]. These concerns have led to studies focusing on characterising vegetation phenology and its drivers especially using remote sensing techniques. The use of these techniques also known as Land Surface Phenology (LSP), offer resources for long-term observations, across large areas, especially areas devoid of ground data [7], [8]. These techniques also offer the capabilities of analysing timeseries data, thereby providing information on the pattern of vegetation development over time. However, despite compelling evidence from the IPCC that a changing climate is having a significant impact on Africa's ecosystem, the magnitude of such impacts have not been fully quantified [9], [10]. Quantifying these impacts depends on a clear understanding of the seasonal vegetation pattern, its trends and its relationship with climatic and non-climatic variables. Therefore, this research aimed to understand the recent vegetation phenology of Africa and its trends over the period 2001 - 2015 using 500 m MODIS EVI time-series data. Analysis of these time-series data can offer information on the developmental pattern of vegetation over the time period and the occurrence of any major trends.

\section{DATA AND METHODS}

\subsection{Data pre-processing and EVI calculation}

The more enhanced MODIS data were used for this research. 16 years (18 Feb 2000 - 24 June 2016) of 33 MODIS/Terra Surface Reflectance 8-Day L3 Global $500 \mathrm{~m}$ SIN Grid V005 data (MOD09A1) tiles were downloaded from NASA's LP DAAC (https://lpdaac.usgs.gov/). Quality assessment (QA) was carried out on each pixel using the 32bit Quality Assurance (QA) layer to filter out residual atmospheric and sensor effects. Only pixels meeting the highest quality (of bands $1-7$ ) which had adjacency and atmospheric correction performed, and all the corrections of MODLAND QA were retained. (see https://lpdaac.usgs.gov/sites/default/files/public/modis/docs/ MODIS_LP_QA_Tutorial-3.pdf for details on the QA assessment procedures).

The Enhanced Vegetation Index (EVI) which has improved sensitivity to high biomass, and to overcomes some of the limitations of NDVI [11], was selected for this study. It includes the blue reflectance band (B) to correct for atmospheric and soil background influences [11], and can be derived according to the following equation: 


$$
E V I=G * \frac{(N I R-\operatorname{Red})}{(L+N I R+C 1 * \operatorname{Red}-C 2 * B \text { lue })}
$$

\subsection{Phenology estimation and phenological trends}

As a result of the non-uniform growing seasons across Africa, 86 "layer stacked" EVI data containing a time-series cycle of two years (i.e., July of year 1 to June of year 3) were used to estimate vegetation phenology parameters [12]. The yearly values of start of season (SOS), end of season (EOS) and length of season (LOS) in each image pixel for the period of 2001 to 2015 were estimated using the methodology described in [12], [13]. The median values for these parameters for the period 2001 to 2015 were estimated and then converted to their corresponding Julian days (i.e. day of year, DOY).

The non-parametric Spearman rank correlation which is more appropriate for non-normally distributed data [14], [15] and simple linear regression test were used to determine the temporal trends in phenological parameters. The Spearman's correlation was used to identify significant temporal trends with significance testing; F-test at 95\% confidence level. Thereafter, a simple linear regression was used to determine the trend in date.

To classify the phenological trends based on land cover, land cover information obtained from the 2013 MODIS/Terra Land Cover Type Yearly L3 Global $500 \mathrm{~m}$ SIN Grid V005 data (MCD12Q1) were downloaded from NASA's LP DAAC (https://lpdaac.usgs.gov/). The most suitable classification scheme, the 17-class International Geosphere Biosphere Programme (IGBP) global vegetation classification scheme analysis [16], was used for this analysis. Further reclassification of land cover types by merging classes with very similar phenological patterns was undertaken. For example, closed shrublands and open shrublands were merged together to give one class of "shrublands". Pixels belonging to non-vegetative land cover were then masked out (see Figure 1).

\section{RESULTS}

\subsection{Spatial variation in phenological parameters}

Results revealed the complex pattern of vegetation phenology in Africa (see Figure 2). The northern latitude (Sahelian, Soudan and Guinean regions) had SOS dates beginning in late February to early August, and EOS dates occurring between late November to the following February. On the other hand, the southern latitudes had SOS dates beginning in August to November, and EOS dates commencing between May-June to August. However, in contrast to the northern latitudes, the extreme north had SOS dates beginning in September to November and EOS occurring between May and August. Similarly, southwestern Africa had a distinctive phenological pattern from the southern latitudes but very similar to patterns for the northern latitudes. The seasonal rainfall patterns observed in these different regions can be attributed to being responsible for the differences in phenological patterns [17], [18].

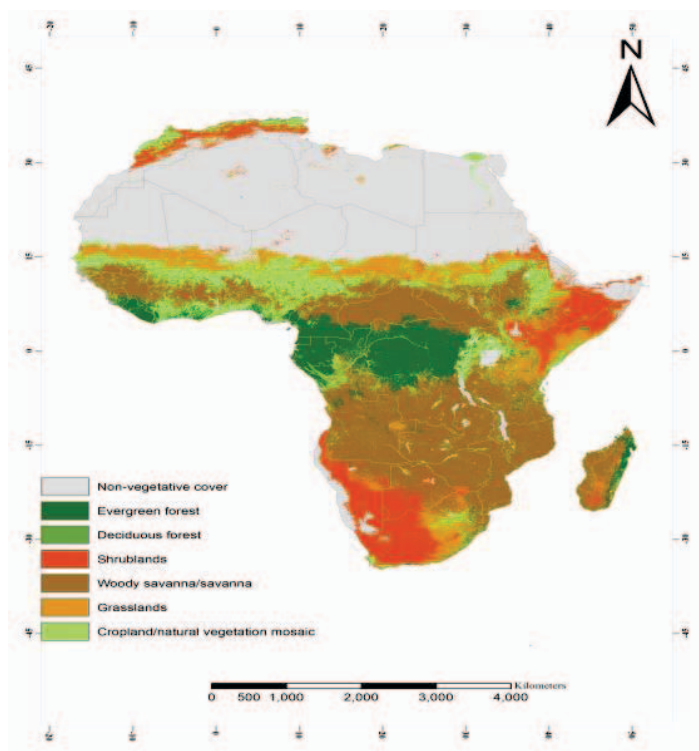

Figure 1. Reclassified 2013 MODIS land cover product (MCD12Q1)
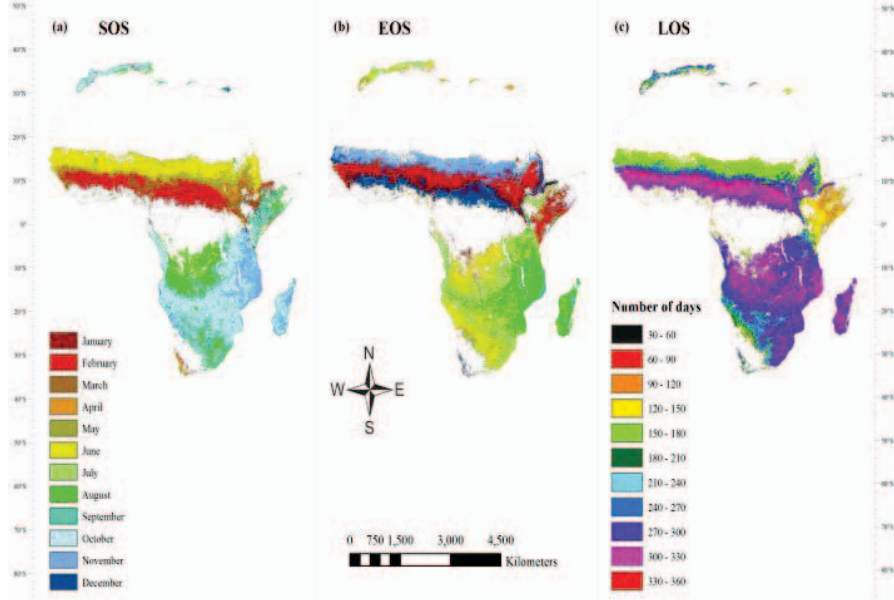

Figure 2. Spatial pattern of median phenological parameters for 2001 to 2015 derived from MODIS EVI data using the inflection point method. (a) median Start of Season (SOS) and (b) median End of Season (EOS) (c) median Length of Season (LOS) shown in number of days.

\subsection{Phenological trend analysis}

Figure 3 shows the significant phenological trends in magnitude of slope for Start of Season (SOS). A summary of the significant statistical trends $(p$-value $<0.05)$ for all 
phenological parameters are displayed in Table 1. Only $11.56 \%$ and $12.97 \%$ of pixels showed significant trends in SOS and EOS, respectively. However, about half of this amount (i.e. $5.72 \%$ of pixels) were significant for LOS. This suggests that in some pixels, despite a changing trend in SOS and/or EOS, there was no change in the LOS. Similarly, a change in LOS was identified despite no apparent changes in SOS or EOS.

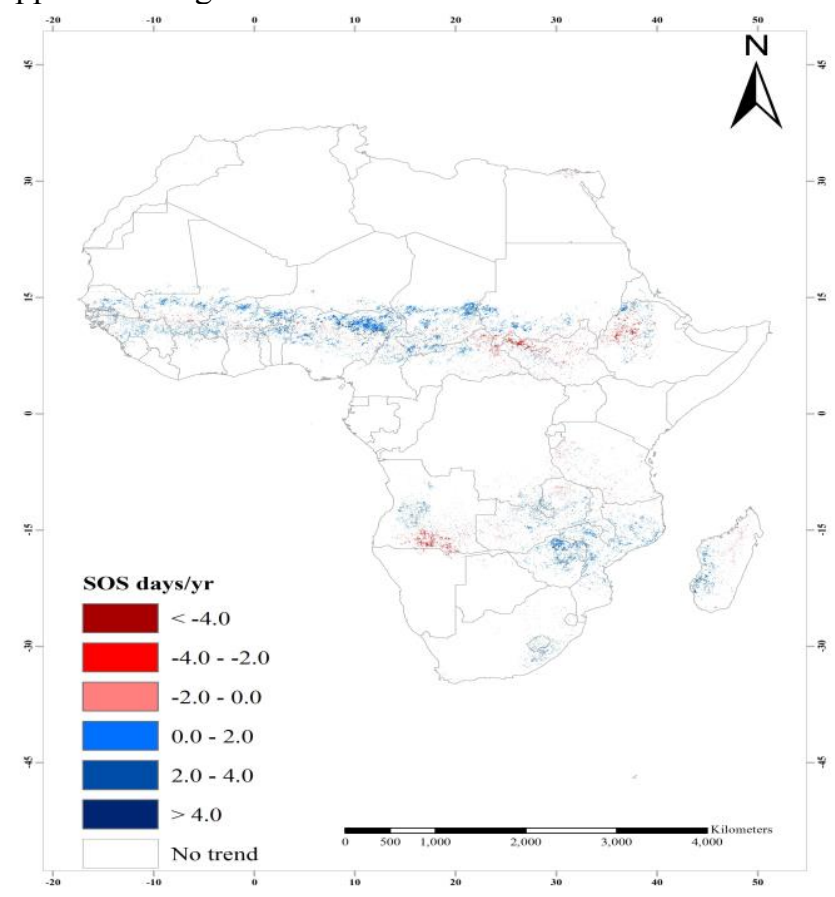

Figure 3. Spatial pattern of Start of Season (SOS) according to the magnitude of slope over time after linear regression with only significant pixels at $p<0.05$.

Table 1. Number and proportion of significant pixels ( $p$-value $<0.05)$ for each phenological parameter

\begin{tabular}{llll}
\hline $\begin{array}{l}\text { Phenological } \\
\text { parameters }\end{array}$ & $\begin{array}{l}\text { Significant } \\
\text { positive }\end{array}$ & $\begin{array}{l}\text { Significant } \\
\text { negative }\end{array}$ & $\begin{array}{l}\text { Overall } \\
\text { Significant }\end{array}$ \\
\cline { 2 - 4 } SOS & 2143262 & 667653 & 2810915 \\
& $(8.82 \%)$ & $(2.75)$ & $(11.56 \%)$ \\
EOS & 2196842 & 956504 & 3153346 \\
& $(9.04 \%)$ & $(3.93 \%)$ & $(12.97 \%)$ \\
LOS & 956697 & 433444 & 139014 \\
& $(3.94 \%)$ & $(1.78 \%)$ & $(5.72 \%)$ \\
\hline
\end{tabular}

Significant phenological trends were identified only in croplands/natural vegetation, woody savanna/savanna, shrublands and grassland with $23 \%$ found in croplands/natural vegetation and $72 \%$ in woody savanna/savannas. These were mostly located in western, central and eastern Africa.

In general, significant SOS trends for croplands were delayed at an approximate rate of 2.3 days year-1, however there was variation in LOS trends. Most croplands in western Africa had positive LOS trends, and in some regions, particularly in Mali and Senegal no significant SOS trends were observed; instead, delayed EOS dates were seen. This, therefore, suggests that delayed EOS is mostly responsible for the increases in LOS.

Similarly, SOS trends were mostly delayed in woody savanna/savanna with about the same rate of 2.4 days year ${ }^{-1}$. However, a very small proportion of pixels (about $0.4 \%$ ) found mostly in central and eastern Africa were negatively significant with rates between -3 and -4 days year ${ }^{-1}$.

\section{DISCUSSION}

This research for the first time described the vegetation phenology of Africa using EVI data derived from a relatively fine spatial resolution of $500 \mathrm{~m}$, and a temporal frequency of 8-days. The spatial variation in the phenological parameters was in strong agreement with previous studies [19]-[21]. Moreover, given that with a finer spatial and temporal resolution less conditional bias can be expected from spatial averaging [22], [23], fewer differences in Julian days were observed with only minor discrepancies of an estimated 5-20 days. Other factors like smoothing techniques and sensor type [22], [24] could also be responsible for these differences.

On the other hand, the observed phenological trends differ in magnitude from previous studies [8], [14], [25]. This could be due to some of the reasons mentioned above and the study period. For example, while in this research LOS trends in northern Nigeria showed negative trends greater than 4 days year ${ }^{-1}$, previous studies [8], [25], [26] revealed positive trends of between 1 to $>2$ days year ${ }^{-1}$. In this research, delayed SOS dates were mostly responsible for this negative LOS trends. Although climatic factors may be responsible for such delays. However, it is important to point out other anthropogenic factors like increased agricultural production and war/conflict which have recently plagued this region, may have significantly impacted on its vegetation dynamics. Therefore, further understanding of the cause of these phenological trends should incorporate the impact of land cover change.

\section{CONCLUSION}

This research mapped the phenology of Africa using fine resolution MODIS data and also described the pattern of phenological trends for the major land cover types of Africa. Most importantly, it highlighted the land cover types that most sensitive to climatic and non-climatic factors. It also calls for the incorporation of land cover change in phenological trend analysis. Hence, we conclude that future phenological studies should employ the use of more finer spatial and temporal resolution data, and consider refinements in the way that land cover changes are accounted for in phenological trend analysis. 


\section{REFERENCES}

[1] M. E. Brown and K. M. de Beurs, "Evaluation of multisensor semi-arid crop season parameters based on NDVI and rainfall," Remote Sens. Environ., vol. 112, no. 5, pp. 2261-2271, 2008.

[2] P. J. CaraDonna, A. M. Iler, D. W. Inouye, and by R. Paul Ehrlich, "Shifts in flowering phenology reshape a subalpine plant community," PNAS, vol. 111, no. 13, pp. 4916-4921, 2014.

[3] M. Zhao, C. Peng, W. Xiang, X. Deng, D. Tian, X. Zhou, G. Yu, H. He, and Z. Zhao, "Plant phenological modeling and its application in global climate change research: overview and future challenges," Environ. Rev., vol. 21, pp. 1-14, 2013.

[4] X. Zhang, M. Friedl, B. Tan, M. Goldberg, and Y. Yu, "Long-Term Detection of Global Vegetation Phenology from Satellite Instruments," Phenol. Clim. Chang., pp. 297-320, 2012.

[5] A. D. Richardson, T. F. Keenan, M. Migliavacca, Y. Ryu, O. Sonnentag, and M. Toomey, "Climate change, phenology, and phenological control of vegetation feedbacks to the climate system," Agric. For. Meteorol., vol. 169, pp. 156-173, Feb. 2013

[6] J. Peñuelas, T. Rutishauser, and I. Filella, "Ecology. Phenology feedbacks on climate change.," Science, vol. 324, no. 2009, pp. 887-888, 2009.

[7] X. Zhang, B. Tan, and Y. Yu, "Interannual variations and trends in global land surface phenology derived from enhanced vegetation index during 1982-2010," Int. J. Biometeorol., vol. 58, no. 4, pp. 547-564, 2014.

[8] Y. Julien and J. a. Sobrino, "Global land surface phenology trends from GIMMS database," Int. J. Remote Sens., vol. 30, no. 13, pp. 3495-3513, 2009.

[9] T. Adole, J. Dash, and P. M. Atkinson, "A systematic review of vegetation phenology in Africa," Ecol. Inform., vol. 34, pp. 117-128, 2016.

[10] IPCC, Climate Change 2014: Impacts, Adaptation, and Vulnerability. Part A: Global and Sectoral Aspects. Contribution of Working Group II to the Fifth Assessment Report of the Intergovernmental Panel on Climate Change. Cambridge University Press, Cambridge, United Kingdom and New York, NY, USA,1132pp, 2014.

[11] A. Huete, K. Didan, W. Van Leeuwen, T. Miura, and E. Glenn, "MODIS vegetation indices," in Land remote sensing and global environmental change, B. Ramachandran, C. O. Justice, and M. J. Abrams, Eds. Springer New York: Springer New York, 2011, pp. 579602.

[12] T. Adole, J. Dash, and P. M. Atkinson, "Characterisation of the Land Surface Phenology of Africa using $500 \mathrm{~m} \mathrm{8-}$ day MODIS EVI time-series data," Remote Sens.

Environ., p. (Under review), 2016.

[13] J. Dash, C. Jeganathan, and P. M. Atkinson, "The use of MERIS Terrestrial Chlorophyll Index to study spatiotemporal variation in vegetation phenology over India," Remote Sens. Environ., vol. 114, no. 7, pp. 1388-1402, 2010.

[14] A. Vrieling, K. M. De Beurs, and M. E. Brown, "Recent trends in agricultural production of Africa based on AVHRR NDVI time series," Proc. SPIE - Int. Soc. Opt.
Eng., vol. 7104, pp. 1-10, 2008.

[15] S. Yue, P. Pilon, and G. Cavadias, "Power of the MannKendall and Spearman's rho tests for detecting monotonic trends in hydrological series," J. Hydrol., vol. 259, no. 14, pp. 254-271, 2002.

[16] D. Liang, Y. Zuo, L. Huang, J. Zhao, L. Teng, and F. Yang, "Evaluation of the Consistency of MODIS Land Cover Product (MCD12Q1) Based on Chinese $30 \mathrm{~m}$ GlobeLand30 Datasets: A Case Study in Anhui Province, China," ISPRS Int. J. Geo-Information, vol. 4, no. 4, pp. 2519-2541, 2015.

[17] J. F. Griffiths, Climates of Africa (World Survey of Climatology). Amsterdam-London-New York: Elsevier, 1971.

[18] B. Liebmann, I. Bladé, G. N. Kiladis, L. M. V Carvalho, G. B. Senay, D. Allured, S. Leroux, and C. Funk, "Seasonality of African precipitation from 1996 to 2009," J. Clim., vol. 25, no. 12, pp. 4304-4322, 2012.

[19] X. Zhang, M. a. Friedl, C. B. Schaaf, A. H. Strahler, and Z. Liu, "Monitoring the response of vegetation phenology to precipitation in Africa by coupling MODIS and TRMM instruments," J. Geophys. Res. D Atmos., vol. 110, pp. 114, 2005.

[20] S. Archibald and R. J. Scholes, "Leaf green-up in a semiarid African savanna - separating tree and grass responses to environmental cues," J. Veg. Sci., vol. 18, no. 4, pp. 583-594, 2007.

[21] K. Guan, E. F. Wood, D. Medvigy, J. Kimball, K. K. C. Ming Pan, J. Sheffield, X. Xu, and M. O. Jones, "Terrestrial hydrological controls on land surface phenology of African savannas and woodlands," $J$. Geophys. Res. Biogeosciences, vol. 119, pp. 1652-1669, 2014.

[22] P. M. Atkinson, C. Jeganathan, J. Dash, and C. Atzberger, "Inter-comparison of four models for smoothing satellite sensor time-series data to estimate vegetation phenology," Remote Sens. Environ., vol. 123, pp. 400-417, Aug. 2012.

[23] X. Zhang, M. a. Friedl, and C. B. Schaaf, "Sensitivity of vegetation phenology detection to the temporal resolution of satellite data," Int. J. Remote Sens., vol. 30, no. 8, pp. 2061-2074, Apr. 2009.

[24] C. Atzberger, A. Klisch, M. Mattiuzzi, and F. Vuolo, "Phenological Metrics Derived over the European Continent from NDVI3g Data and MODIS Time Series," Remote Sens., vol. 6, no. 1, pp. 257-284, Dec. 2013.

[25] B. W. Heumann, J. W. Seaquist, L. Eklundh, and P. Jönsson, "AVHRR derived phenological change in the Sahel and Soudan, Africa, 1982-2005," Remote Sens. Environ., vol. 108, pp. 385-392, 2007.

[26] A. Vrieling, J. De Leeuw, and M. Y. Said, "Length of growing period over africa: Variability and trends from 30 years of NDVI time series," Remote Sens., vol. 5, pp. 982-1000, 2013 